\title{
Synthesis and Characterization of Thermally Stable Hydroxyapatite
}

\author{
Meriem Harkat ${ }^{1}$, Safia Alleg ${ }^{2 *}$, Rafik Chemam ${ }^{1}$, Sonia Azzaza ${ }^{2}$, Majda Mokhtari² ${ }^{2}$ Essebti Dhahri ${ }^{3}$ \\ ${ }^{1}$ Laboratoire de Physique de Rayonnements (LPR), Department of Physics, Badji Mokhtar Annaba University, B.P. 12, Annaba \\ 23000, Algeria \\ ${ }^{2}$ Laboratoire de Magnetisme et Specroscopie des Solides (LM2S), Department of Physics, Badji Mokhtar Annaba University, \\ B.P. 12, Annaba 23000, Algeria \\ ${ }^{3}$ Laboratoire de Physique Appliquée, Faculté des Sciences, Université de Sfax, B.P. 1171, Sfax 3000, Tunisia
}

Corresponding Author Email: safia_alleg@yahoo.fr

https://doi.org/10.18280/acsm.450106

Received: 25 June 2020

Accepted: 12 December 2020

\section{Keywords:}

hydroxyapatite, wet chemical route, XRD,

Rietveld refinement, SEM

\begin{abstract}
Nanocrystalline and thermally stable hydroxyapatite (HA) powder with nominal composition of $\mathrm{Ca}_{10}\left(\mathrm{PO}_{4}\right)_{6}(\mathrm{OH})_{2}$ was prepared by wet chemical route from calcium hydroxide $\mathrm{Ca}(\mathrm{OH})_{6}$ and mono ammonium phosphate $\mathrm{NH}_{4} \mathrm{H}_{2} \mathrm{PO}_{4}$ as calcium and phosphate sources, respectively. The effect of calcination temperature on the structure, microstructure, molecular bonding, thermal behavior and morphology was investigated by X-ray diffraction patterns (XRD), Fourier Transform Infra-Red (FT-IR), Raman spectroscopy, thermogravimetry (TGA), differential thermal analysis (DTA) and scanning electron microscopy (SEM) coupled with energy dispersive X-ray spectroscopy (EDS) analysis. The XRD patterns of the as-prepared and calcined powders exhibit a single phase of hydroxyapatite. The crystallite size of as-prepared and calcined HA is in the range of 44-182 nm. FT-IR and Raman spectroscopy results are in good agreement with XRD ones. The EDS analysis reveals the presence of all elements. The thermal stability of the synthesized powders is evidenced by TGA/DTA scans which show a weight loss smaller than $2 \%$.
\end{abstract}

\section{INTRODUCTION}

Biomaterials are widely used to repair, fill, extend and reconstruct damaged tissue. The most promising replacement biomaterials are those with bioactive properties such as calcium phosphate-based bioceramics groups (hydroxyapatite HA $\left(\mathrm{Ca}_{10}\left(\mathrm{PO}_{4}\right)_{6}\left(\mathrm{OH}_{2}\right)\right.$ and tricalcium phosphate TCP), owing to their good properties such as biocompatibility, osteoconductivity, bioactivity, non-toxicity and noninflammatory $[1,2]$. Therefore, its synthesis has received a great deal of interest both in academic and industrial areas [37]. In general, HA is prepared by two main approaches. The first one is solid state reaction which produces oxyapatite instead of HA and must be controlled by water vapor flow, and the second one belongs to wet chemical route including aqueous precipitation, hydrothermal techniques and hydrolysis of other calcium phosphates. The wet chemical route is widely used owing to its low temperature synthesis, its ability to generate nanocrystalline powders and the fact that it ensures a convenient fusion of the apatite crystals as well as a homogenous molecular mixing $[2,6,8]$.

$\mathrm{Ca}\left(\mathrm{NO}_{3}\right)_{2} \mathrm{H}_{2} \mathrm{O},\left(\mathrm{NH}_{4}\right)_{2} \mathrm{HPO}_{4}$ and $\mathrm{H}_{3} \mathrm{PO}_{4}$ precursors have been used as calcium and phosphate sources, respectively in many studies [8-13]. It has been reported that the optimum temperature of calcination for $\mathrm{HA}$ is $600^{\circ} \mathrm{C}$. Above this temperature, HA decomposes into tetracalicum phosphate, tricalcium phosphate, calcium oxide and amorphous calcium phosphate. Some of these compounds are undesirable in medical applications because of their fast dissolution in vivo which accelerates the implant failure [14].
The aim of the present work is to propose a cheap and quick method for the synthesis of highly nanocrystalline and thermally stable $\mathrm{HA}$ powder by the wet chemical route using $\mathrm{Ca}(\mathrm{OH})_{2}\left(\mathrm{H}_{2} \mathrm{O}\right)_{6}$ and $\mathrm{NH}_{4} \mathrm{H}_{2} \mathrm{PO}_{4}$ as calcium and phosphate sources, respectively. The structure, microstructure, morphology and thermal stability of the as-prepared and calcined powders were investigated by means of X-ray diffraction (XRD), Fourier Transform Infra-Red (FT-IR), Raman spectroscopy, thermogravimetry, differential thermal analysis (TGA/DTA) and scanning electron microscopy (SEM) coupled with energy dispersive X-ray spectroscopy (EDS).

\section{EXPERIMENTAL PROCEDURE}

\subsection{Powder synthesis}

Calcium hydroxide $\mathrm{Ca}(\mathrm{OH})_{2} \cdot\left(\mathrm{H}_{2} \mathrm{O}\right)_{6}$, monoamonium dihydrogen phosphate $\mathrm{NH}_{4} \mathrm{H}_{2} \mathrm{PO}_{4}$ and ammonia $\mathrm{NH}_{4} \mathrm{OH}$ were used to prepare nanocrystalline HA powders. Calcium and phosphorous precursors were dissolved separately in distilled water. The aqueous $\mathrm{NH}_{4} \mathrm{H}_{2} \mathrm{PO}_{4}$ solution was added by drop wise to $\mathrm{Ca}(\mathrm{OH})_{2} .\left(\mathrm{H}_{2} \mathrm{O}\right)_{6}$ aqueous solution and was subjected to hot magnetic agitation at room temperature for 2 hours. An appropriate amount of ammonium solution $\mathrm{NH}_{4} \mathrm{OH}$ was added to keep the $\mathrm{pH}$ close to 9-10.The precipitate was then washed with distilled water several times to eliminate impurities and then filtered using Buchner funnel and vacuum pump. After filtration, the product $\mathrm{HA} 1$ was dried at $60^{\circ} \mathrm{C}$ overnight. The as-dried HA1 powder was crushed using an agate mortar and 
then calcined at 600,800 and $1000^{\circ} \mathrm{C}$ for $2 \mathrm{~h}$. These temperatures are assigned, respectively, to $\mathrm{HA} 2\left(600^{\circ} \mathrm{C}\right), \mathrm{HA}_{3}$ $\left(800^{\circ} \mathrm{C}\right)$ and $\mathrm{HA} 4\left(1000^{\circ} \mathrm{C}\right)$ samples. The obtained powders were compacted into pellets of $5 \mathrm{~mm}$ in diameter under a pressure of $50 \mathrm{MPa}$ using a uniaxial hydraulic press. Figure 1 displays the steps for samples preparation.

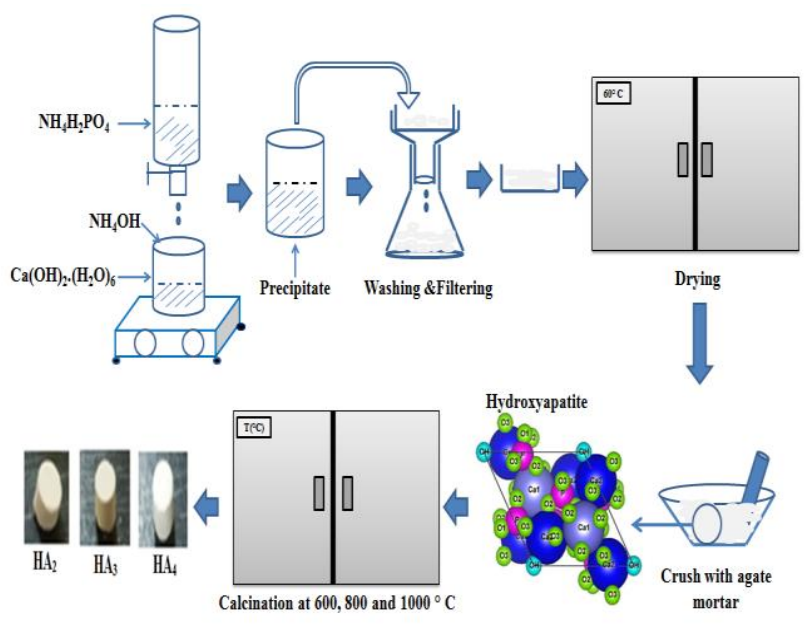

Figure 1. Synthesis method of hydroxyapatite samples

\subsection{Characterization techniques}

The phase identification of the raw and calcined HA powders was performed by XRD on a PanAlytical Empyrian diffractometer, in a $(\theta-\theta)$ Bragg-Brentano geometry, using a $\mathrm{CuK} \alpha$ radiation $(\lambda=1.5406 \AA)$ and a step size of $1^{\circ}$ from $5^{\circ}$ to $139^{\circ}$. Molecular bonding properties of the powders were examined with FTIR and Raman spectroscopy analysis using Brucker instrument, between 4000 and $400 \mathrm{~cm}^{-1}$ for the FTIR and from 100 to $3500 \mathrm{~cm}^{-1}$ for the Raman spectroscopy. Powder morphology was followed by a Vega3Tescan SEM apparatus equipped with energy dispersive X-ray spectroscopy (EDS) analysis. The weight loss and thermal stability of the HA powders were studied by means of TGA/DTA SDT600 instrument, under argon atmosphere, in the temperature range of $82-1200^{\circ} \mathrm{C}$ and a heating rate of $10^{\circ} \mathrm{C} / \mathrm{min}$.

\subsection{Phase analysis by the Rietveld method}

The Rietveld's refinement $[15,16]$ of the XRD patterns is achieved by the MAUD program [17]. The peak shapes can be affected by both the sample (crystallite size, strain/stress, and defects) and the instrument (geometry, radiation source, etc.). The crystallite size and the root mean square microstrain (r.m.s.) were evaluated using the isotropic model. The shape of the peaks in the experimental diffraction patterns was well described by an asymmetric pseudo-Voigt function [16]. The instrumental parameters, including three Caglioti parameters for full-width at half-maximum (FWHM), two asymmetry factors and two parameters for Gaussian content of peak profiles, were fixed to the values obtained from the standard material lanthanum boride. The background of each pattern was modeled as a third-order polynomial function. The peak positions were corrected for zero-shift error by successive refinements. Then, the crystal structure parameters such as lattice parameters, phase proportion, crystallite size, r.m.s. (root mean square) microstrain, atomic positions ( $\mathrm{x}, \mathrm{y}, \mathrm{z})$, site occupancy factor, (SOF) and Debye-Waller factor (B) were refined.
The selection of the most satisfactory fitting is made on the base of the minimization of the difference between the observed and simulated powder diffraction patterns which was carried out by using the reliability parameters Rwp (weighted residual factor), $\mathrm{R}_{\mathrm{B}}$ (Bragg factor) and $\mathrm{Rexp}$ (expected residual factor). The goodness of fit (GoF) is obtained by comparing Rwp with Rexp (Gof = Rwp / Rexp). Refinement continues till convergence is reached with the value of the quality factor, GoF approaching 1, which confirms the goodness of refinement.

\section{RESULTS AND DISCUSSIONS}

\subsection{XRD analysis}

The XRD patterns of the as-prepared and calcined HA powders at different temperatures are shown in Figure 2. The diffraction peaks are characteristic of the calcium hydroxyapatite crystals. As the temperature increased from $600^{\circ} \mathrm{C}$ to $1000^{\circ} \mathrm{C}$, several peaks of the hydroxyapatite become more distinct and also the width of the peaks become narrower which suggests an increase in the crystallite size of the coherent diffraction domains. In addition, a very small additional peaks situated at $2 \theta=27^{\circ}$ and $2 \theta=31^{\circ}$ are observed for the calcined sample at $1000^{\circ} \mathrm{C}$. These peaks belong to $\beta$ Tricalcium phosphate $(\beta$-TCP) phase with chemical formula $\mathrm{Ca}_{3}\left(\mathrm{PO}_{4}\right)_{2}$ and a volume fraction of about $4 \%$. The formation of this phase may be due to the partially decomposition of carbonated hydroxyapatite into $\beta$-TCP during the calcination process at $1000^{\circ} \mathrm{C}[6,12,13,18-20]$.

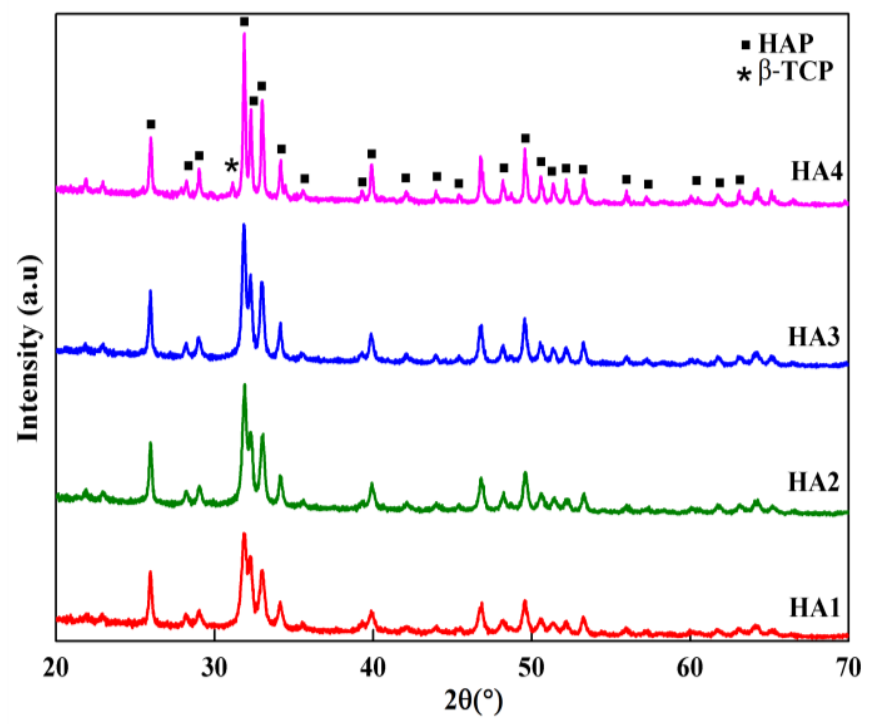

Figure 2. XRD patterns of the as-prepared and calcined HA powders

The typical refinement plots of raw and calcined HA powders are shown in Figure 3. The best Rietveld refinement of the HA1, HA2 and HA3 patterns is obtained by the introduction of hexagonal hydroxyapatite nanocrystalline phase with cell parameters $a=b=9.432 \AA$ and $c=6.881 \AA$ and space group $P 6_{3} / \mathrm{m}$. However, for $\mathrm{HA}_{4}$ sample, the best refinement is obtained with two phases: hexagonal hydroxyapatite and hexagonal $\beta$-TCP phase with the space group R3c:H and lattice parameters $a=b=10.4352 \AA$ and $c=$ $37.4029 \AA$. Because the peaks' broadening is related to the 
microstructural characteristics (crystallite size and microstrain), we have applied the Popa approach for the anisotropic microstructure analysis [21], implemented in the MAUD code as "Popa rules". It resulted that each sample is constituted of elongated nanocrystallites (NC) which can be approximated by circular ellipsoids. The deduced structural and microstructural parameters from the Rietveld refinement of the XRD patterns are summarized in Table 1. One observes an increase in the average crystallite size of the HA powders with increasing the calcination temperature. The higher value of crystallite size $(182 \mathrm{~nm})$ was reached for HA4 sample. Similar phenomenon was observed previously $[11,22]$.
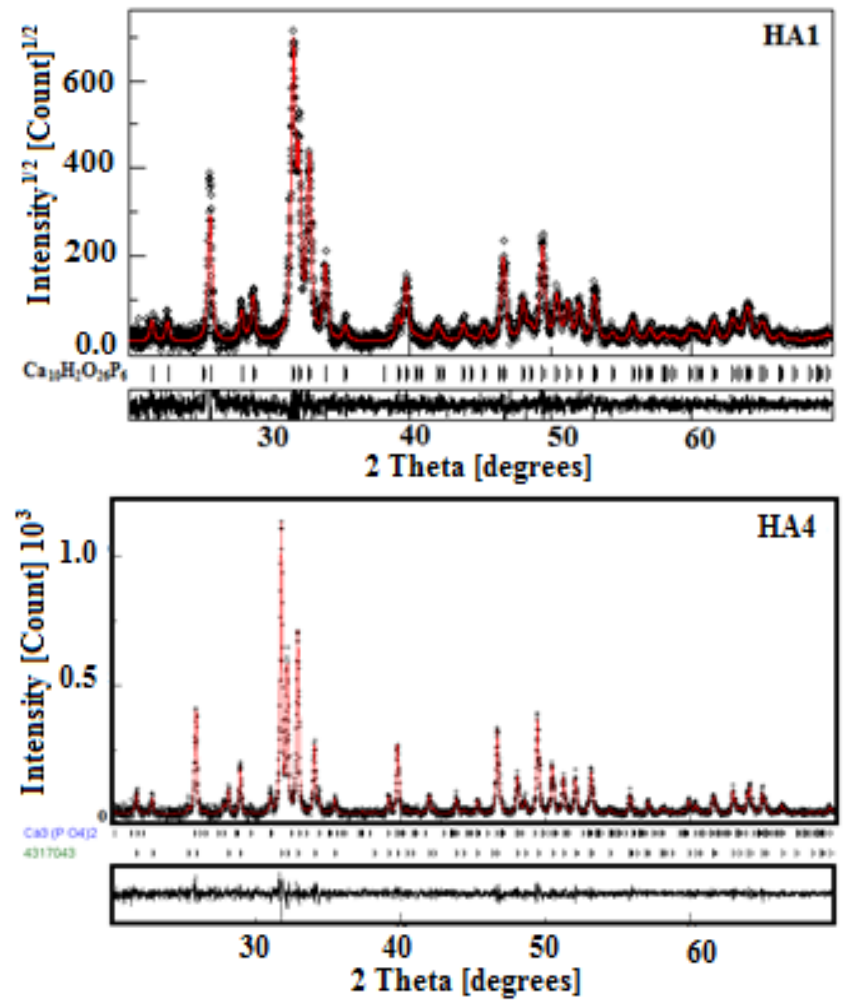

Figure 3. Rietveld refinement of the XRD patterns of HA1 and HA4 powders

Table 1. Lattice parameters (a, c), crystallite size (d), porosity $(P)$ and density $\left(\rho, \mathrm{g} / \mathrm{cm}^{3}\right)$

\begin{tabular}{|c|c|c|c|c|}
\hline Sample & HA1 & HA2 & HA3 & HA4 \\
\hline$a(\AA)\left( \pm 10^{-3}\right)$ & 9.4234 & 9.4174 & 9.4196 & 9.4210 \\
\hline$c(\AA)\left( \pm 10^{-3}\right)$ & 6.8869 & 6.8851 & 6.8832 & 6.8817 \\
\hline$d(n m)( \pm 2)$ & 44 & 52 & 64 & 182 \\
\hline$\rho_{\mathrm{m}}$ & --- & 1.91 & 1.51 & 1.58 \\
\hline$\rho X-$ ray & 3.12 & 3.14 & 3.11 & 3.11 \\
\hline $\mathbf{P}$ & --- & 0.39 & 0.51 & 0.49 \\
\hline
\end{tabular}

Small fluctuations in lattice parameters $a$ and $c$ of HA phase are observed with increasing the calcination temperature. The lattice distortion can be confirmed by the Debye-Waller factor changes during calcination process. The Debye-Waller parameter $B$ is a measure of the displacement of atoms from their ideal positions. It consists of static and thermal components. According to the diffraction theory derived by Krivoglaz [23], BS is related to the static displacement of the atom from the equilibrium position caused by defects such as vacancies, interstitials and dislocations. However, BT is the contribution from the thermal vibrations of the atom around the equilibrium lattice site and is grain size independent [24].
It was reported that the static DWP in various NC samples increases by $100-900 \%$ compared to the equilibrium values [25] due to the existence of the lattice distortion in the nanocrystalline lattice.

The lattice distortion can be confirmed also by the atomic coordinate changes during the calcination process. The deduced atomic coordinates from the Rietveld refinement indicate that the local arrangement for the nanocrystalline structures is slightly different from that in perfect crystal. In fact, the increase of the calcination temperature may lead to a drift of atoms from their equilibrium positions. Table 2 shows small changes in the atomic coordinates $(\mathrm{x}, \mathrm{y}, \mathrm{z})$, and occupancy of the calcined $\mathrm{HA}$ at $1000^{\circ} \mathrm{C}$ compared to the raw sample for some elements. It is well known that the structure of hexagonal HA consists of $\mathrm{Ca}$ atoms distributed in two sites: site (I) and site (II). In the first site, $\mathrm{Ca}_{1}$ is located and surrounded by six atoms of oxygen $\left(\mathrm{O}_{1}(2), \mathrm{O}_{2}(2), \mathrm{O}_{3}(2)\right)$ connected to phosphate groups, with mean distances of 2.409 $\AA$, and related to three other atoms of oxygen $\left(\mathrm{O}_{3}(3)\right)$ distanced by $2.821 \AA$. In the second site, calcium $\mathrm{Ca} 2$ is surrounded by six oxygen atoms $\left(\mathrm{O}_{1}, \mathrm{O}_{2}, \mathrm{O}_{3}(4)\right)$ and one atom of oxygen related to $\mathrm{OH}$ group; the mean distances between $\mathrm{Ca}_{2}$, atoms of oxygen and $\mathrm{OH}$ group are $2.461 \AA$ and $2.720 \AA$, respectively. As depicted in Figure 4, the tetrahedral arrangement links $\mathrm{Ca}_{1}$ to $\mathrm{Ca}_{2}$. It consists of $\mathrm{P}$ atoms related to four atoms of oxygen $\left(\mathrm{O}_{1}, \mathrm{O}_{2}, \mathrm{O}_{3}(2)\right)$ distanced by $1.534 \AA$. The obtained inter-atomic distances are in good agreement with those reported earlier [26]

Table 2. Atomic positions (x, y, z) and occupancy (Occ.) in the raw and calcined $\mathrm{HA}$ at $1000^{\circ} \mathrm{C}$ (HA4)

\begin{tabular}{cccccc}
\hline Sample & Atom & $\mathbf{x}$ & $\mathbf{y}$ & $\mathbf{z}$ & Occ. \\
\hline \multirow{5}{*}{ Raw HA } & Ca1 & 0.3333 & 0.6666 & 0.00 & 0.3333 \\
& Ca2 & 0.2500 & -0.0055 & 0.25 & 1 \\
& P & 0.3984 & 0.3695 & 0.25 & 0.5 \\
& O1 & 0.3285 & 0.4885 & 0.25 & 0.5 \\
& O2 & 0.5851 & 0.4600 & 0.25 & 0.5 \\
& O3 & 0.3432 & 0.257 & 0.068 & 1 \\
& OH & 0 & 0 & 0.193 & 0.195 \\
\hline \multirow{5}{*}{ HA4 } & Ca1 & 0.3333 & 0.6666 & 0.0017 & 0.3253 \\
& Ca2 & 0.2500 & -0.0047 & 0.25 & 1 \\
& P & 0.3981 & 0.3667 & 0.25 & 0.5 \\
& O1 & 0.3281 & 0.4841 & 0.25 & 0.5 \\
& O2 & 0.5859 & 0.4625 & 0.25 & 0.5 \\
& O3 & 0.3368 & 0.2508 & 0.0658 & 1 \\
& OH & 0 & 0 & 0.181 & 0.217 \\
\hline
\end{tabular}

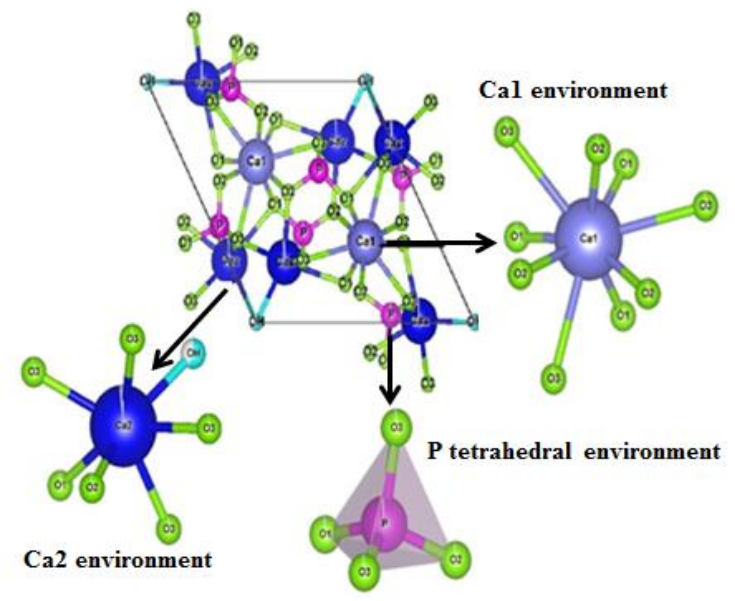

Figure 4. Unit cell and environment atoms of $\mathrm{Ca} 1, \mathrm{Ca} 2$ and $\mathrm{P}$ of HA sample 
The determination of the porosity in the studied samples was performed by using the following relation [27]:

$$
P=1-\frac{\rho_{m}}{\rho_{X-\text { ray }}}
$$

where, $\rho_{\mathrm{m}}$ is the bulk density and $\rho_{\mathrm{X}}$-ray is the X-ray density. $\rho_{m}$ is calculated by the following relation [27]:

$$
\rho_{m}=\frac{m}{\pi r^{2} h}
$$

where, $\mathrm{m}$ is the mass of pellet; $\mathrm{r}$ is the radius and $\mathrm{h}$ is the thickness of the pellet. The calculated porosity values are found to be in the range of $0.39-0.49$ (Table 1).

\subsection{FT-IR spectroscopy}

FT-IR spectroscopy is a very useful tool for investigating vibrational properties of the synthesized materials. The band positions and absorption peak not only depend on the chemical composition and structure of the samples but on their morphology also [28]. FT-IR spectra of raw and calcined HA samples in the range from 400 to $4000 \mathrm{~cm}^{-1}$ are shown in Figure 5. Analysis of spectra was done on the basis of the published results of NPs in the literature. Hence, the peak situated at $1015 \mathrm{~cm}^{-1}$ can be attributed to $v_{1}$ stretching mode of (P-O) group [8, 11, 12, 14, 29]. The observed peaks at 472, 590 and $957 \mathrm{~cm}^{-1}$ might be assigned, respectively, to $v_{3}$ asymmetric stretching of $\mathrm{P}-\mathrm{O}$ group, $v_{2}$ symmetric and $v_{4}$ asymmetric deformation of O-P-O bond [8, 11, 12, 14, 29]. The bands assigned to the stretching mode of hydroxyl group $\mathrm{O}-\mathrm{H}$ are depicted in the range of $470-663 \mathrm{~cm}^{-1}$ and at 3573 $\mathrm{cm}^{-1}$. Several works have reported the same peaks positions of nano-hydroxyapatite but with characteristic peaks of carbonate group [12]. The FT-IR results confirm the XRD ones.

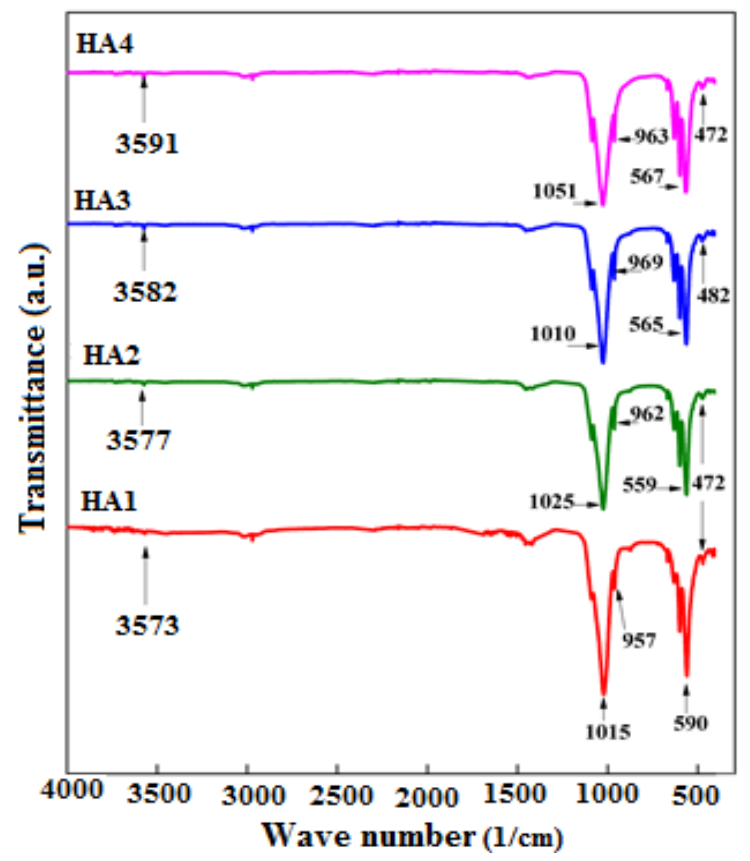

Figure 5. FT-IR spectra of the as-prepared and calcined HA powders at different temperatures

\subsection{Raman spectroscopy}

Figure 6 displays the Raman spectra of raw and calcined HA at different temperatures from 100 to $3500 \mathrm{~cm}^{-1}$. HA is an intense Raman scatter and shows very little signal noise with small amount of fluorescence in $\mathrm{HA}_{1}$ and $\mathrm{HA}_{2}$ samples. The vibrational normal modes of tetrahedron are well known and gives rise to four different frequencies: $v_{1}, v_{2}, v_{3}, v_{4}$. In fact, $v_{1}=962 \mathrm{~cm}^{-1}$ and $v_{3}=1047 \mathrm{~cm}^{-1}$ frequencies correspond to symmetric and asymmetric stretching of P-O group whereas $v_{2}=428 \mathrm{~cm}^{-1}$ and $v_{4}=594 \mathrm{~cm}^{-1}$ can be linked, respectively, to the doubly and triply degenerated O-P-O bending character [30-41]. Beside the important reduction of the intensity of the peak positioning at $962 \mathrm{~cm}^{-1}$ with the increase of the calcination temperature, it is observed the appearance of new peaks at 230 and $418 \mathrm{~cm}^{-1}$ frequencies. These assignments can be associated with internal P-O group of the $\beta$-TCP phase, whereas the less intense peak at $130 \mathrm{~cm}^{-1}$ is due to the external lattice mode. This result is in good agreement with XRD and FT-IR ones.

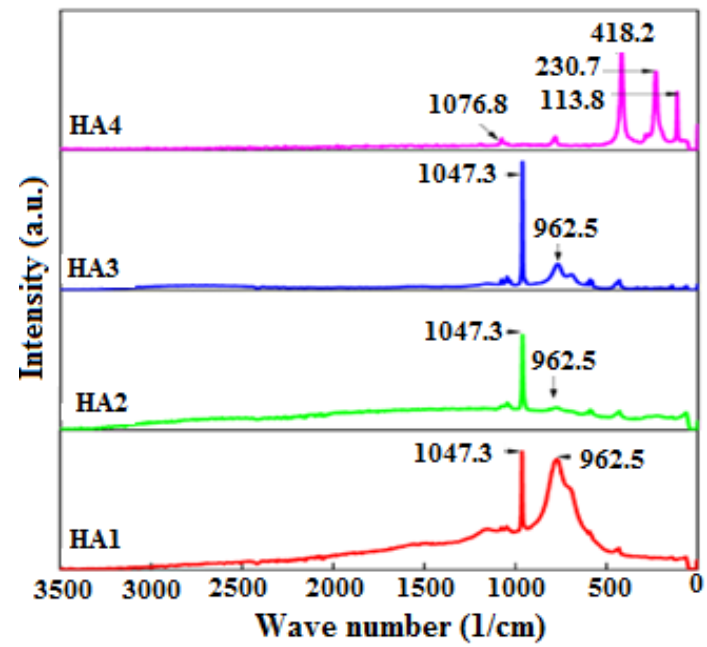

Figure 6. Raman spectra of the as-prepared and calcined HA powders at different temperatures

\subsection{Thermal analysis}

Thermal analysis is usually used to identify the working temperature range at which bioceramics are applicable and to determine the temperature of phase transformation. The latter depends largely on the synthesis techniques of the HA powder [30]. TGA/DTA analyses shown in Figure 7 were conducted to confirm the thermal stability of the synthesis powder HA1. TGA scan shows a total mass loss of about $1.54 \%$ in the temperature range of $31-1200^{\circ} \mathrm{C}$. In the temperature range of $31-500^{\circ} \mathrm{C}$, the maximum weight loss of about $0.8 \%$ can be ascribed to the evaporation of the adsorbed water. However, the mass loss $(0.08 \%)$ between 500 and $800^{\circ} \mathrm{C}$, can be linked to the loss of lattice water and finally, between 800 and $1200^{\circ} \mathrm{C}$, the weight loss of about $0.66 \%$ might be attributed to the beginning of the decomposition of $\mathrm{Ca}_{10}\left(\mathrm{PO}_{4}\right)_{6}$ to $\mathrm{Ca}_{3}\left(\mathrm{PO}_{4}\right)_{2}$. DTA curve of the as-prepared powder exhibits an obvious thermal stability owing to the total absence of endothermic and exothermic peaks. This mass loss confirms the XRD results of the calcined powder at $1000^{\circ} \mathrm{C}$ as well as the peaks positioning in the Raman spectra of the same sample. The low percentage of the weight loss proves the thermal stability of the synthesis powder. 


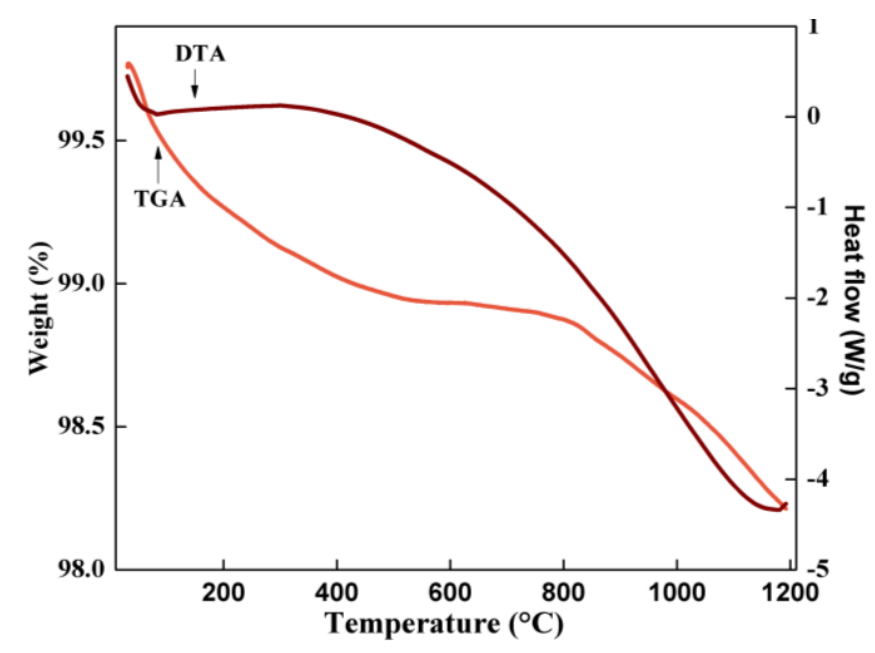

Figure 7. TGA/DTA curves of the raw HA powder

\subsection{Morphology}

Figure 8a shows SEM micrographs of raw and calcined HA powders at different temperature. For the HA1 sample, the particles which have non-spherical shape are in nanometer range with mean size of $\sim 170 \mathrm{~nm}$ in length and $\sim 90 \mathrm{~nm}$ in width. All elements $(\mathrm{Ca}, \mathrm{P}, \mathrm{O})$ are present in this powder as it is illustrated in the cartography (Figure $8 \mathrm{~b}$ ). As the calcination temperature increases, the morphology of particles for all samples is clearly irregular with plate-like morphology and the most of the hydroxyapatite particles are agglomerated (Figure 9). The average size of these poly-dispersive agglomerations increases and varies from 1 to $8 \mu \mathrm{m}$ for the smallest one, and from 20 to $50 \mu \mathrm{m}$ for the biggest one.
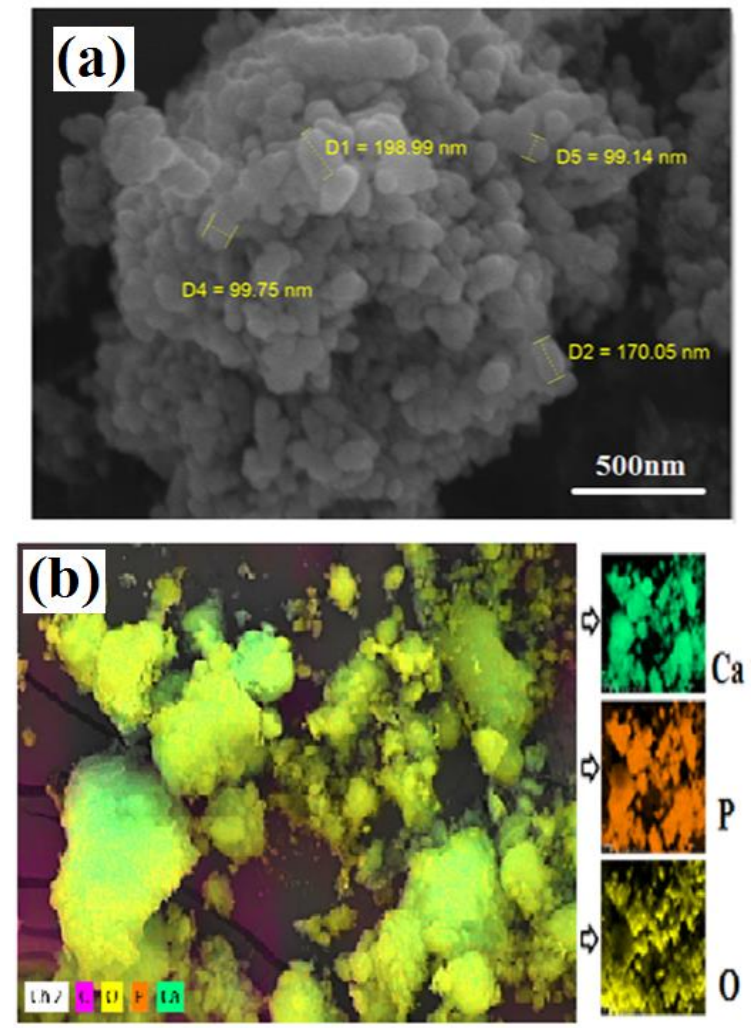

Figure 8. SEM micrograph and cartography of $\mathrm{Ca}, \mathrm{P}$ and $\mathrm{O}$ in the raw HA powder

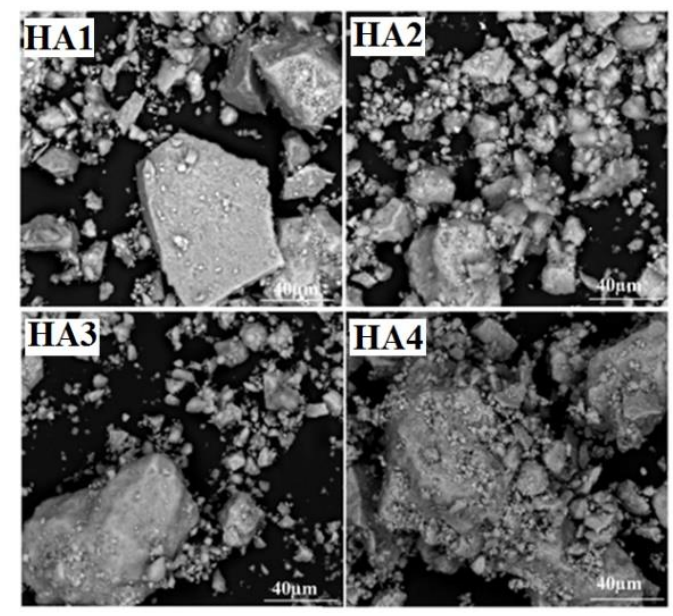

Figure 9. SEM images of the raw and calcined HA powders
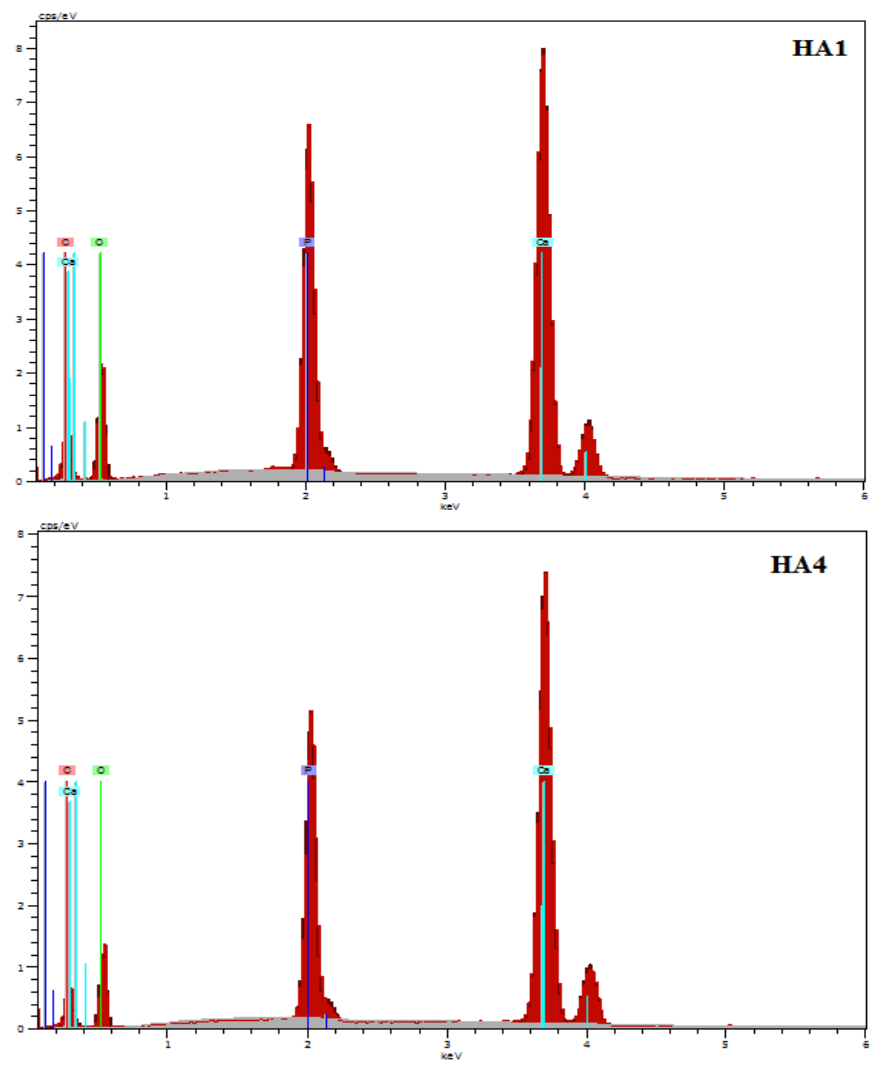

Figure 10. Typical EDS spectra of raw and calcined HA

Elemental analysis of the HA powders was performed by EDS. The measurements were performed on several zones of the powders. The qualitative analysis shows the presence of the three elements $\mathrm{Ca}, \mathrm{O}$, and $\mathrm{P}$ (Figure 10). With increasing the calcination temperature, the percentage of calcium and phosphorous elements varies slightly (Table 3). Moreover, it is important to highlight that no additional peaks are detected in all EDS spectra, indicating the absence of impurities and excludes any contamination from the preparation media or atmosphere.

Table 3. Elemental analysis

\begin{tabular}{ccccc}
\hline $\begin{array}{c}\text { Element } \\
\text { (wt. \%) }\end{array}$ & HA1 & HA2 & HA3 & HA4 \\
\hline $\mathrm{Ca}$ & 32.51 & 41.56 & 45.74 & 46.8 \\
$\mathrm{P}$ & 12.75 & 14.0 & 15.46 & 15.4 \\
$\mathrm{O}$ & 54.75 & 44.44 & 38.8 & 37.8 \\
\hline
\end{tabular}




\section{CONCLUSIONS}

A quick, easy, simple and cheap method has been used to prepare nanocrystalline and thermally stable HA powder. The XRD results reveal the presence of a single phase of HA up to $800^{\circ} \mathrm{C}$. A small amount $(\sim 4 \%)$ of $\beta$-TCP secondary phase is observed at $1000^{\circ} \mathrm{C}$. The SEM micrographs show that the powder consists of nanoparticles which agglomerate on a random basis with increasing calcination temperature. Both the FT-IR and Raman spectroscopies exhibit the characteristic bands of HA. TGA/DTA scans reveal a weight loss of about $1.54 \%$ in the temperature range of $10-1200^{\circ} \mathrm{C}$.

\section{ACKNOWLEDGMENT}

This work has been supported by the DGRSDT/MESRS Algeria.

\section{REFERENCES}

[1] Haider, A., Haider, S., Han, S.S., Kang, I.K. (2017). Recent advances in the synthesis, functionalization and biomedical applications of hydroxyapatite: review. RSC Advances, 7:

7442-7458 https://doi.org/10.1039/C6RA26124H

[2] Fihri, A., Len, C., Varma, R.S., Solhy, A. (2017). Hydroxyapatite: A review of syntheses, structure and applications in heterogeneous catalysis. Coordination Chemistry Reviews, 347: 48-76. https://doi.org/10.1016/j.ccr.2017.06.009

[3] Wu, S.C., Hsu, H.C., Hsu, S.K., Chang, Y.C., Ho, W.F. (2015). Effects of heat treatment on the synthesis of hydroxyapatite from eggshell powders. Ceramics International, 41(9): 10718-10724 https://doi.org/10.1016/j.ceramint.2015.05.006

[4] Piccirillo, C., Castro, P.M.L. (2017). Calcium hydroxyapatite-based photocatalysts for environment remediation: Characteristics, performances and future perspectives. Journal of Environmental Management, 193: 79-91. https://doi.org/10.1016/j.jenvman.2017.01.071

[5] Ben-Arfa, A.E.B., Salvado, I.M.M., Frade, J.R., Pullar, C.R. (2016). Fast route for synthesis of stoichiometric hydroxyapatite by employing the Taguchi method. Materials and Design, 109: 547-555. https://doi.org/10.1016/j.matdes.2016.07.083

[6] Suparto, I.H., Putri, D.K. (2015). Synthesis of Hydroxyapatite from Rice Fields Snail Shell (bellamyajavanica) through wet method and pore modification using chitosan. Procedia Chemistry, 17: 27 35. https://doi.org/10.1016/j.proche.2015.12.120

[7] Prezas, P.R., Melo, B.M.G., Costa, L.C., Valente, M.A., Lanc, M.C., Ventura, J.M.G., Pinto, L.F.V., Graça, M.P.F. (2017). TSDC and impedance spectroscopy measurements on hydroxyapatite, beta-tricalcium phosphate and hydroxyapatite/beta-tricalcium phosphate biphasic bioceramics. Applied Surface Science, 424(1): 28-38. https://doi.org/10.1016/j.apsusc.2017.02.225

[8] Yeltena, A., Yilmaza, S. (2016). Various parameters affecting the synthesis of the hydroxyapatite powders by the wet chemical precipitation technique. Materials Today: $\quad$ Proceedings, 3(9): 2869-2876. https://doi.org/10.1016/j.matpr.2016.07.006

[9] Agougui, H., Aissa, A., Debbabi, M., Grusselle, M., Thouvenot, R. (2010). Surface modification of mixed hydroxuapatites $\mathrm{Ca}(10-\mathrm{x}) \mathrm{Ni}_{\mathrm{x}}\left(\mathrm{PO}_{4}\right)_{6}(\mathrm{OH})_{2}$ by grafting phenyl phosphonic dichloride. Annales de Chimie Sciences des Matériaux, 35(4): 195-208. http://dx.doi.org/10.3166/acsm.35.195-208

[10] Sendi, N., Bachoua, H., Badraoui, B., Elaloul, E. (2013). Physico-chemical characterization of nickel substituted calcium hydroxyapatites. Annales de Chimie Sciences des Matériaux, 38(3-4): 95-104. http://dx.doi.org/10.3166/acsm.38.95-104

[11] Abidi, S.S.A., Murtaza, Q. (2014). Synthesis and characterization of nano-hydroxyapatite powder using wet chemical precipitation reaction. Journal of Materials Science Technology, 30(4): 307-310. https://doi.org/10.1016/j.jmst.2013.10.011

[12] Ramesha, S., Natashaa, A.N., Tana, C.Y., Banga, L.T., Niakana, A., Purbolaksonoa, J., Chandranc, H., Chinga, C.Y., Rameshd, S., Tenge, W.D. (2015). Characteristics and properties of hydroxyapatite derived by sol-gel and wet chemical precipitation methods. Ceramics International, 41(9): 10434-10441. https://doi.org/10.1016/j.ceramint.2015.04.105

[13] Kramer, E., Podurgiel, J. (2014). Control of hydroxyapatite nanoparticle morphology using wet synthesis techniques: Reactant addition rate effects. Materials Letters, 131: 145-147. https://doi.org/10.1016/j.matlet.2014.05.105

[14] Chandanshive, B.B., Rai, P., Rossi, A.L., Ersen, O., Khushalani, D. (2013). Synthesis of hydroxyapatite nanotubes for biomedical applications. Materials Science and Engineering, 33(5): 2981-2986. https://doi.org/10.1016/j.msec.2013.03.022

[15] Rietveld, H.M. (1967). Line profiles of neutron powderdiffraction peaks for structure refinement. Acta Crystallographica, 22: 151-152. https://doi.org/10.1107/S0365110X67000234

[16] Rietveld, H.M. (1969). A profile refinement method for nuclear and magnetic structures. Journal of Applied Crystallography, 2: 65-71. https://doi.org/10.1107/S0021889869006558

[17] Lutterotti, L., Scardi, P., Maistrelli, P. (1992). LSI - A computer program for simultaneous refinement of material structure and microstructure. Journal of Applied Crystallography, 25: 459-462. https://doi.org/10.1107/S0021889892001122

[18] Fathi, M.H., Hanifi, A., Mortazavi, V. (2008). Preparation and bioactivity evaluation of bone-like hydroxyapatite nanopowders. Journal of Materials Processing Technology, 202(1-3): 536-542. https://doi.org/10.1016/j.jmatprotec.2007.10.004

[19] Ungureanu, D.N., Angelescu, N., Ion, R.M., Stoian, E.V., Rizescu, C.Z. (2011). Synthesis and characterization of hydroxyapatite nanopowders by chemical precipitation. Recent Researches in Communications, Automation, Signal Processing, Nanotechnology, Astronomy and Nuclear Physics, 296-301.

[20] Mansour, F., El-Dek, S.I., Ahmed, M.A., Abd-Elwahab, S.M., Ahmed, M.K. (2015). Effect of preparation conditions on the nanostructure of hydroxyapatite and brushite phases. Applied Nanoscience, 6: 991-1000. https://doi.org/10.1007/s13204-015-0509-4

[21] Popa, N.C. (1998). The (hkl) dependence of diffraction- 
line broadening caused by strain and size for all Laue groups in Rietveld refinement. Journal of Applied Crystallography, 31: 176-180. https://doi.org/10.1107/S0021889897009795

[22] Sanosh, K.P., Chu, M.C., Balakrishnan, A., Kim, T.N., Cho, S.J. (2009). Preparation and characterization of nano-hydroxyapatite powder using sol gel method. Bulletin of Material Science, 32(5): 465-470. https://doi.org/10.1007/s12034-009-0069-X

[23] Krivoglaz, M. (1969). Theory of X-Ray and ThermalNeutron Scattering by Real Crystals. Plenum Press, New York.

[24] Qian, H., Wang, S.C., Zhao, Y.H., Lu, K. (2002). Microstrain effect on thermal properties of nanocrystalline $\mathrm{Cu}$. Acta Materialia, 50(13): 3425-3434. https://doi.org/10.1016/S1359-6454(02)00155-6

[25] Lu, K., Zhao, Y.H. (1999). Experimental evidences of lattice distortion in nanocrystalline materials. Nanostructured Materials, 12(1-4): 559-562. https://doi.org/10.1016/S0965-9773(99)00183-X

[26] Dhand, V., Rhee, K.Y., Park, S.J. (2014). The facile and low temperature synthesis of nanophase hydroxyapatite crystals using wet chemistry. Materials Science and Engineering, 36: 152-159. https://doi.org/10.1016/j.msec.2013.11.049

[27] Mahmood, A., FarooqWarsi, M., Naeem Ashiq, M., Ishaq, M. (2013). Substitution of La and Fe with Dy and $\mathrm{Mn}$ in multiferroic $\mathrm{La}_{-\mathrm{x}} \mathrm{Dy}_{\mathrm{x}} \mathrm{Fe}_{1-\mathrm{y}} \mathrm{Mn}_{\mathrm{y}} \mathrm{O}_{3}$ nanocrystallites. Journal of Magnetism and Magnetic Materials, 327: 6470. https://doi.org/10.1016/j.jmmm.2012.09.033

[28] Yang, Z., Ye, Z.Z., Xu, Z., Zhao, B.H. (2009). Effect of the morphology on the optical properties of $\mathrm{ZnO}$ nanostructures. Physica E: Low-Dimensional Systems and Nanostructures, 42(2): 116-119. https://doi.org/10.1016/j.physe.2009.09.010

[29] Khalida, M., Mujahida, M., Aminb, S., Rawatc, R.S., Nusaird, A., Deenc, G.R. (2013). Effect of surfacetant and heat treatment on morphology surface area and crystallinity in hydroxyapatite nanocrystals. Ceramics International, $\quad 39(1)$ : 39-50. https://doi.org/10.1016/j.ceramint.2012.05.090

[30] Jansen, J.A., Leon, B. (2009). Thin calcium phosphate coatings for medical implants. New York: Springer. https://doi.org/ 10.1007/978-0-387-77718-4

[31] Slosarczyk, A., Paluszkiewicz, C., Gawlicki, M., Paszkiewicz, Z. (1997). The FTIR spectroscopy and QXRD studies of calcium phosphate based materials produced from the powder precursors with different $\mathrm{Ca} / \mathrm{P}$ ratios. Ceramics International, 23(4): 297-304. https://doi.org/10.1016/S0272-8842(96)00016-8

[32] Elliot, J.C. (1994). Structure and Chemistry of the Apatites and Other Calcium Orthophosphates. Studies in Inorganic Chemistry, Elsevier.

[33] Cusco, R., Guitian, F., de Aza, S., Arttis, L. (1998). Differentiation between Hydroxyapatite and /ITricalcium phosphate by means of $\mu$-Raman spectroscopy. Journal of the European Ceramic Society, 18(9): 1301-1305. https://doi.org/10.1016/S09552219(98)00057-0

[34] Koutsopoulos, S. (2002). Synthesis and characterization of hydroxyapatite crystals: A review study on the analytical methods. Journal of Biomedical Materials Research, $62(4)$ :

600-612. https://doi.org/10.1002/jbm.10280

[35] Sauer, G.R., Zunic, W.B., Durig, J.R., Wuthier, R.E. (1994). Fourier transform Raman spectroscopy of synthetic and biological calcium phosphates. Calcified Tissue International, 54: 414-420. https://doi.org/10.1007/BF00305529

[36] Tsuda, H., Arends, J. (1993). Raman spectra of human dental calculus. Journal of Dental Research, 72(12): 1609-1613. https://doi.org/10.1177/00220345930720121401

[37] Griffith, W.P. (1970). Raman studies on rock-forming minerals. Part II. Minerals containing $\mathrm{MO}_{3}, \mathrm{MO}_{4}$, and $\mathrm{MO}_{6}$ groups. Journal of the Chemical Society A: Inorganic, Physical, Theoretical, 286-291. https://doi.org/10.1039/J19700000286

[38] de Aza, P.N., Guitian, F., Santos, C., de Aza, S., Cusco, R., Artus, L. (1997). Vibrational investigation of calcium phosphate compounds: Comparison between hydroxyapatite and $\beta$-tricalcium phosphate. Chemistry of Materials, $9(4): \quad 916-922$. https://doi.org/10.1021/cm9604266

[39] Rehrnan, I., Smith, R., Hench, L.L., Bonfield, W. (1995). Structural evaluation of human and sheep bone and comparison with synthetic hydroxyapatite by FT-Raman spectroscopy. Journal of Biomedical Materials Research, 29(10): 1287-1294. https://doi.org/10.1002/jbm.820291016

[40] O'Shea, D.C., Bartlett, M.L., Young, R.A. (1974). Compositional analysis of apatites with laser-raman spectroscopy: $(\mathrm{OH}, \mathrm{F}, \mathrm{Cl})$ apatites. Archives of Oral Biology, 19(11): 995-1006. https://doi.org/10.1016/0003-9969(74)90086-7

[41] Liu, D., Troczynski, T., Tseng, J.W. (2001). Water-based sol-gel synthesis of hydroxyapatite: Process development. Biomaterials, 22(13): 1721-1730. https://doi.org/10.1016/S0142-9612(00)00332-X

\section{NOMENCLATURE}

$$
\begin{aligned}
& \text { a, b, c } \\
& \text { R3c:H } \\
& \text { d } \\
& \text { P } \\
& x, y, z
\end{aligned}
$$

\section{Greek symbols}

$\lambda$

$\rho_{\mathrm{m}}$

$\rho_{\mathrm{X} \text {-ray }}$

$v$

$\rho$

\section{Subscripts}

$\begin{array}{ll}\text { XRD } & \begin{array}{l}\text { X ray diffraction } \\ \text { Fourier transform infrared } \\ \text { spectroscopy }\end{array} \\ \text { SEM } & \begin{array}{l}\text { Scanning electron microscopy } \\ \text { Energy dispersive X-ray } \\ \text { Epectroscopy }\end{array} \\ \text { TGA } & \begin{array}{l}\text { Thermogravimetry analysis } \\ \text { DTA }\end{array} \\ \text { HA } & \text { Hydferential thermal analysis (DTA) }\end{array}$

Lattice parameters, А.

Space group.

Crystallite size, $\mathrm{nm}$.

Dimensionless Porosity.

Atomic positions
Wave length, $\AA$.
Bulk density, $\mathrm{g} / \mathrm{cm}^{3}$.
$\mathrm{X}$-ray density
Frequency, $\mathrm{cm}^{-1}$.
Density, $\mathrm{g} / \mathrm{cm}^{3}$. 
GoF

Rexp

$\mathrm{R}_{\mathrm{B}}$

Rwp

r.m.s
Goodness of fit

Expected residual factor

Bragg factor

Weighted residual factor

Root mean square
FWHM

TCP

SOF

$\mathrm{B}$

NC
Full width half maximum

Tricalcium phosphate

Site occupancy factor

Debye Waller factor

Nanocrystallite 